\title{
Morphometric analysis and three-dimensional computed tomography reconstruction of the long bones of femoral and crural regions in Van cats
}

\author{
O. Yılmaz'® ${ }^{1}$, i. Demircioğlu²® \\ 'Department of Anatomy, Faculty of Veterinary Medicine, Van Yüzüncü Yıl University, Van, Turkey \\ ${ }^{2}$ Department of Anatomy, Faculty of Veterinary Medicine, Harran University, Şanlıurfa, Turkey \\ [Received: 21 June 2020; Accepted: 6 September 2020]
}

Background: This study was conducted to determine the morphometric features and to make the three-dimensional (3D) reconstruction of the images obtained by computed tomography (CT) of the main long bones (femur, tibia, fibula) in Van cats, and to reveal the biometric differences between these measurement values of both sexual dimorphism and homotypic variations.

Materials and methods: A total of 16 adult Van cats, 8 male and 8 female, were used in the study. The pelvic limb long bones of the cats, which were anesthetized with the ketamine-xylazine combination, were scanned with a CT device and their images were obtained. These images were converted to a 3D structure by means of MIMICS 20.1 (The Materialise Group, Leuven, Belgium) software programme. Then, morphometric, volumetric, surface arae measurements of these bones were calculated and statistical analyses were performed.

Results: In the analysis, it was observed that right greatest length (GL), left GL, right greatest length from caput ossis femoris (GLC), left greatest breadth of the distal end $(B d)$, right volume $(V)$, and left $V$ measurement values of the femur; left $G L 1$, right greatest breadth of the proximal end (BP), right $B d$, left $B d$, right smallest breadth of the diaphysis (SD), right $V$, left $V$, and right surface area (SA) measurement values of the tibia; right $V$, left $V$, right $S A$, and left $S A$ measurement values of the fibula were statistically significantly higher in male cats than in female cats $(p<0.05)$. The volume and surface area measurement values of the femur, tibia and fibula of male and female cats were determined as $8.57 \pm 1.33 \mathrm{~cm}^{3}$ and $7.00 \pm 0.49 \mathrm{~cm}^{3}, 64.28 \pm 6.72 \mathrm{~cm}^{2}$ and $59.42 \pm 4.72 \mathrm{~cm}^{2} ; 7.56 \pm 1.28 \mathrm{~cm}^{3}$ and $6.15 \pm 0.52 \mathrm{~cm}^{3}, 56.89 \pm 6.47 \mathrm{~cm}^{2}$ and $52.72 \pm 3.15 \mathrm{~cm}^{2} ; 1.10 \pm 0.17 \mathrm{~cm}^{3}$ and $0.83 \pm 0.05 \mathrm{~cm}^{3}, 14.18 \pm 1.61 \mathrm{~cm}^{2}$ and $11.95 \pm 0.48 \mathrm{~cm}^{2}$, respectively. Conclusions: The statistical differences between the sexes in terms of the measurement parameters of the femur, tibia and fibula in adult Van cats were determined. We believe that these differences can be used in determining morphological variations of Van cats. In addition, it is thought that the data obtained from the present study would be beneficial to veterinary physicians in the clinical application areas in order to evaluate the pathological conditions related to these bones and to the studies in the field of zooarchaeology. (Folia Morphol 2021; 80, 1: 186-195)

Key words: computed tomography, femur, fibula, three-dimensional reconstruction, tibia, Van cat 


\section{INTRODUCTION}

Living around and named after the Van Lake region of Turkey, Van cats are an attractive breed of domestic cats with their distinctive eye coloration (one eye can be yellow and the other can be blue, both can be yellow, or both can be blue), soft fur, affection for swimming, hunting capabilities, cleanliness, and intelligence. In 22 April 2006, Van cats were licensed and registered with the communiqué no. 2006/16 as a breed of domestic cat with all their distinctive properties, and are now officially under protection of the Republic of Turkey [6]. There are only a handful of studies in literature, however, regarding the osteological properties of these cats [46-48].

Known also as "the thigh bone", femur (os femoris) is the strongest of all the long bones. It usually has a cranioventral bearing along the skeletal structure, and it plays a significant role during the forward motion of the body [14]. Meanwhile, "the ossa cruris" structure is another formation of the long bones of the pelvic limbs, and consists of the combination of the tibia and fibula bones. Tibia is a long, tubular bone and is the stronger of the two as it shoulders the weight of the body. It is located towards the medial surface of the leg, and has joints with the femur at the proximal end and with ossa tarsi at the distal end. Located towards the lateral surface, the fibula is weaker and does not have a joint with femur at the proximal end. On the distal end, however, it has a limited amount of contact with ossa tarsi [4]. In ruminants, the proximal end of the fibula is found in contact with the outer rim of the condyles lateralis tibae, and it has a regressed corpus. Its distal end, it joins the formation of os malleolare. In equidae, the proximal end of the fibula makes a joint with tibia, but the distal end only reaches halfway down the range of tibia where it ends with a pointy edge. Sus and carnivore species have a fully developed fibula, but it's separated from tibia with a formation known as "spatium interosseum cruris". This gap, which is enclosed with soft tissue, goes almost all the way down to the distal edge in Sus species, while it's only limited to the proximal region in carnivores [15].

In recent years, medical imaging systems, computed tomography (CT), and three-dimensional (3D) reconstruction software become commonly utilized tools when trying to determine the morphological properties of the anatomical structures in the skeletal systems of animals, particularly those of small, pet animals like cats and dogs. These systems are also being used to obtain osteometric and volumetric measurement results, to evaluate any potential developmental, metabolic, inflammatory, or degenerative anomalies, and to investigate numerous other pathological situations like traumas, dislocations, fractures, or neoplasia $[26,45]$. Anthropological studies also commonly use these methods and 3D modelling in tandem to determine the morphological properties of long bones and to perform various measurements on them $[8,17,21]$.

Various studies have been performed to determine the anatomical and osteometrical properties of the main long bones of the pelvic limbs (femur, tibia, fibula) of different animal species, like mole-rats (Spalax leucodon Nordmann) [34], African giant rats (Cricetomys gambianus Waterhouse) [27], grasscutter rodents (Thryonomys swinderianus, Temminck-1827) [29], guinea pigs (Cavia porcellus) [37], feral pigs (Sus scrofa) [19], martens (Martes fonia) [3], badgers (Meles meles) [32], squirrels (Sciurus vulgaris) [31], hedgehogs hedgehog (Erinaceus europaeus L.) [35], porcupines (Hystrix Cristata) [49], chinchillas (Chinchilla lanigera) [10], lumholtz tree-kangaroo (Dendrolagus lumholtzii) [40], Anatolian bobcats (Lynx lynx) [30], New Zealand rabbits (Oryctolagus cuniculus) [1, 16, 36], marmosets (Callithrix jacchus) [9], brown bears (Ursus arctos) [13], deers (Hippocamelus bisulcus) [41], sheeps (Ovis aries) [2], gazelles (Gazella subgutturosa) [12], foxes (Vulpes vulpes and Alopex lagopus) [24], dogs (Canis lupus familiaris) [28, 43], and domestic cats (Felis catus and Felis domestica) $[5,16]$. No study was found when the existing literature was searched for long bones of the pelvic limbs of Van cats, however. This study was, therefore, performed with the aim of creating 3D models of the pelvic limb long bones of Van cats using CT scans and imaging of different anatomical structures of these bones, and to obtain osteometric and volumetric measurements and to determine any potential biometrical difference in these measured values with regards to sexual dimorphism and homotypic variations.

\section{MATERIALS AND METHODS}

A total of 16 adult Van cats (8 males and 8 females) obtained from Van Yuzuncu Yil University Van Cat Research and Application Centre was used in this study. The ages of the cats varied between 3 and 8 years, and their live body masses (W) varied between 5810 and 8050 grams. Ad libitum cat feed and tap water was provided to these cats until the day before the study. The study received the approval of the Van Yuzuncu Yil 
Table 1. Studied parameters and abbreviations (according to Von den Driesch, 1976 [44])

\begin{tabular}{|c|c|c|}
\hline Parameter & Abbreviation & Definition \\
\hline \multicolumn{3}{|c|}{ Measurement points and abbreviations of the femur in Van cats } \\
\hline 1 & $\mathrm{GL}$ & Greatest length: distance between the proximal and the distal end [mm] \\
\hline 2 & GLC & Greatest length from caput ossis femoris: distance between the caput ossis femoris and the distal end [mm] \\
\hline 3 & Bp & Greatest breadth of the proximal end [mm] \\
\hline 4 & $\mathrm{Bd}$ & Greatest breadth of the distal end [mm] \\
\hline 5 & Dc & Greatest depth of the caput ossis femoris [mm] \\
\hline 6 & SD & Smallest breadth of the diaphysis (Corpus ossis femoris) [mm] \\
\hline 7 & V & Volume of the femur $\left[\mathrm{cm}^{3}\right]$ \\
\hline 8 & SA & Surface area of the femur $\left[\mathrm{cm}^{2}\right]$ \\
\hline \multicolumn{3}{|c|}{ Measurement points and abbreviations of the tibia in Van cats } \\
\hline 1 & GL1 & Greatest length: distance between the proximal and the distal end [mm] \\
\hline 2 & Bp & Greatest breadth of the proximal end [mm] \\
\hline 3 & $\mathrm{Bd}$ & Greatest breadth of the distal end [mm] \\
\hline 4 & SD & Smallest breadth of the diaphysis (Corpus tibiae) [mm] \\
\hline 5 & V & Volume of the tibia $\left[\mathrm{cm}^{3}\right]$ \\
\hline 6 & SA & Surface area of the tibia $\left[\mathrm{cm}^{2}\right]$ \\
\hline \multicolumn{3}{|c|}{ Measurement points and abbreviations of the fibula in Van cats } \\
\hline 1 & GL2 & Greatest length: distance between the proximal and the distal end [mm] \\
\hline 2 & V & Volume of the fibula $\left[\mathrm{cm}^{3}\right]$ \\
\hline 3 & SA & Surface area of the fibula $\left[\mathrm{cm}^{2}\right]$ \\
\hline
\end{tabular}

University Local Ethical Board for Animal Experimentation (Decision no: 2020/02-27.02.2020). The cats included in the study were numbered, and were not provided any feed starting the day before the study. Anaesthetisation of the cats for the scanning process was performed using a combination of ketamine $(15 \mathrm{mg} / \mathrm{kg}$, IM, Ketaso ${ }^{\circledR} 10 \%$ injectable, Interhas Veterinary Medicines, Ankara) and xylazine (1-2 mg/kg, IM, Alfazyne ${ }^{\circledR}$ $2 \%$ injectable, Ege - Vet Veterinary Medicines, Izmir).

A 16-section multi-sequential CT device (Somatom Sensetion 16; Siemens Medical Solutions, Erlangen, Germany) located in Van Yuzuncu Yil University Medical Faculty Radiology Department was used to obtain the CT scans of the cats. A disposable sheet was placed onto the gantry of the device, and the cats were laid onto this sheet head-first in prone position (ventral decubitus) to achieve symmetry. The device parameters for the CT scan were as follows: KV/Effective mAs/Rotation time (sec) 120/120/0.75; gantry rotation period $420 \mathrm{~ms}$; physical detector collimation, $16 \times 0.6 \mathrm{~mm}$; section thickness $0.4 \mathrm{~mm}$; final section collimation $32 \times 0.63 \mathrm{~mm}$; feed/rotation $6 \mathrm{~mm}$; Kernel, u90u; increment $0.5 \mathrm{~mm}$; and resolution $512 \times 512$ pixels. Setting of the dosage parameters and the scanning process itself were performed on the basis of standard protocols established by the literature $[18,39]$. The images obtained were saved in DICOM format.

These images were then transported to the MIMICS 20.1 (The Materialise Group, Leuven, Belgium) software and were reconstructed. Osteometric measurements were then performed on the 3D models of the femur, tibia, and fibula bones. The measurement points specified in the literature were used during the morphometric measurements [44]. Once the morphometric measurements were complete, the surface area and volume of each of the bones were calculated. The definitions and abbreviations for the measured osteometric parameters are presented in Table 1. Nomina Anatomica Veterinaria [25] was used as the terminology basis throughout the study. Weighing of the cats included in the study was performed using a digital scale $\left(\mathrm{TESS}^{\circledR},{ }^{\circledR}\right.$ RP-LCD, Çomak Terazi, İstanbul).

\section{Statistical analysis}

Van cat pelvic limb long bones (femur, tibia, and fibula) were modelled in 3D environment based on the CT images of the cats obtained as part of study, and Shapiro-Wilk test $(n<50)$ was used to determine if the value distribution of the data obtained from these models was normal. Since the distribution of the values 


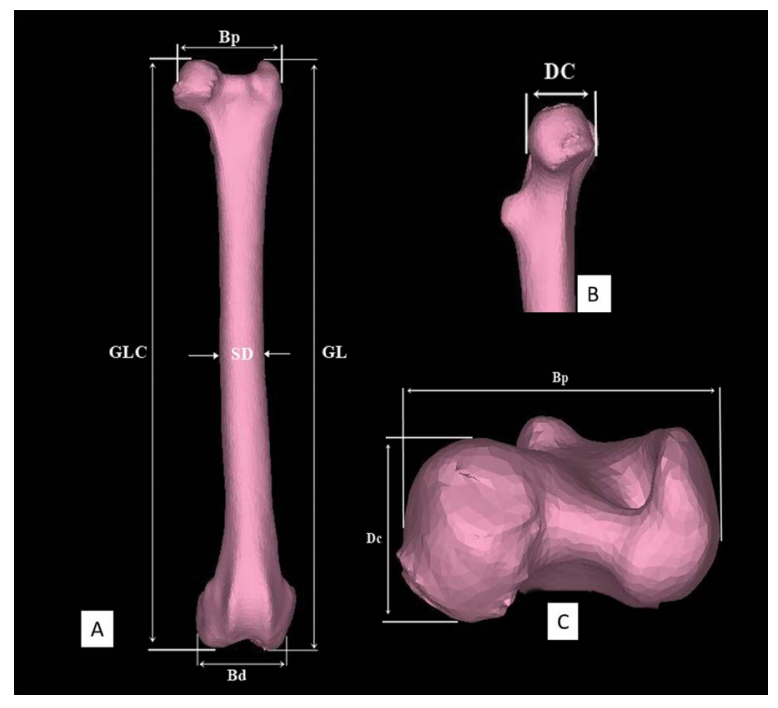

Figure 1. Measurement points from cranial (A), upper medial (B), and dorsal (C) of the femur in Van cats; GL — greatest length; $\mathrm{GLC}$ - greatest length from caput ossis femoris; Bp — greatest breadth of the proximal end; $\mathrm{Bd}$ - greatest breadth of the distal end; Dc — greatest depth of the caput ossis femoris; SD — smallest breadth of the diaphysis (Corpus ossis femoris).

weren't normal in general, a number of non-parametric tests were performed throughout the rest of the study. The defining statistics for the measured properties in this study are presented as mean, standard deviation, and minimum and maximum values. Wilcoxon test was used to compare the measurements for left and right side bones. Comparisons between the sexes were performed using Mann-Whitney- $U$ test. The correlations between the measurements were investigated through Spearman Correlation coefficient calculations, and were separately performed for each sex. Statistical significance threshold was taken as $(\alpha)$ $5 \%$, and SPSS (IBM SPSS for Windows, Ver.23) package software was used for calculations.

\section{RESULTS}

The volume and surface area measurements of the Van cat pelvic limb femur, tibia, and fibula were performed as part of this study. The morphometric measurement parameters and 3D reconstructions are presented in Figures 1-3 with regards to the measurement point locations on bones. These results were then compared in terms of sexual dimorphism and homotypic variations, and are presented in Tables 2-7. Any statistically significant differences between the results $(p<0.05)$ were recorded.

Table 2 presents the defining statistics for femurs' morphometric measurement results and the comparison of the sexes in terms of homotypic variations.

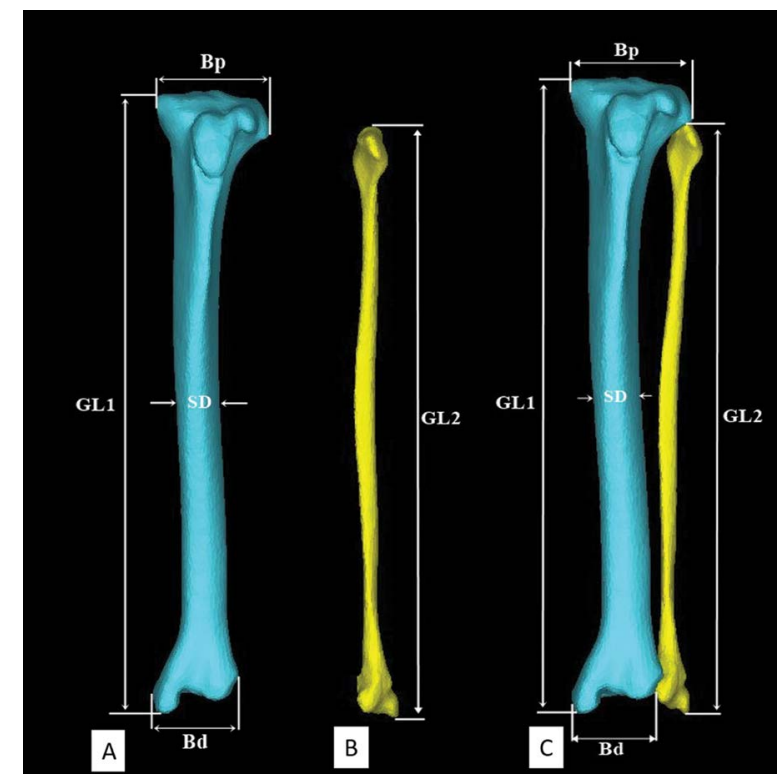

Figure 2. Measurement points from cranial of the tibia (A), fibula (B), and ossa cruris (C) in Van cats; GL1 - greatest length of the femur; $\mathrm{Bp}$ - greatest breadth of the proximal end; $\mathrm{Bd}$ - greatest breadth of the distal end; SD - smallest breadth of the diaphysis (Corpus tibiae); GL2 — greatest length of the fibula.

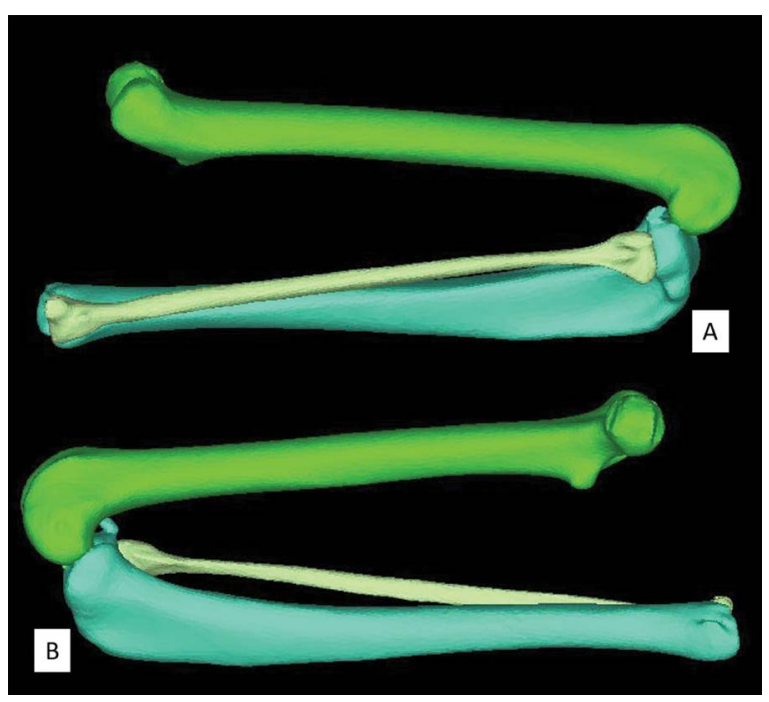

Figure 3. Three-dimensional reconstruction of the pelvic limb long bones (femur, tibia, fibula) from lateral (A) and medial (B) in Van cats (flexion position).

Accordingly, right greatest length (GL), left $G L$, right greatest length from caput ossis femoris (GLc), left greatest breadth of the distal end $(\mathrm{Bd})$, right volume $(V)$, and left $V$ values were found to be higher in males in a statistically significant manner, compared to females $(p<0.05)$. When the left and right femur defining statistics were compared within each sex, right smallest breadth of the diaphysis (SD) 
Table 2. Descriptive statistics and homotypic variations of the biometric parameters of the femur obtained from three-dimensional reconstruction of computed tomography images in Van cats

\begin{tabular}{|c|c|c|c|c|c|c|c|}
\hline \multirow[b]{2}{*}{ Parameter } & \multicolumn{3}{|c|}{ Male } & \multicolumn{3}{|c|}{ Female } & \multirow[t]{2}{*}{$\mathbf{P}^{*}$} \\
\hline & Mean \pm SD & Minimum & Maximum & Mean \pm SD & Minimum & Maximum & \\
\hline Right GL & $108.79 \pm 4.81$ & 102.47 & 117.60 & $103.44 \pm 2.84$ & 100.01 & 107.30 & 0.016 \\
\hline Left GL & $108.88 \pm 5.04$ & 103.07 & 118.01 & $103.18 \pm 3.02$ & 99.31 & 107.46 & 0.016 \\
\hline Right GLC & $110.23 \pm 5.34$ & 101.55 & 117.31 & $103.99 \pm 3.24$ & 99.44 & 110.27 & 0.021 \\
\hline Left GLc & $109.12 \pm 5.11$ & 102.36 & 118.23 & $104.84 \pm 2.79$ & 102.24 & 110.22 & 0.059 \\
\hline Right Bp & $20.48 \pm 0.82$ & 19.14 & 21.37 & $19.63 \pm 0.95$ & 18.24 & 20.91 & 0.059 \\
\hline Left Bp & $20.27 \pm 1.05$ & 19.13 & 22.03 & $19.20 \pm 0.98$ & 17.56 & 20.77 & 0.066 \\
\hline Right Bd & $18.40 \pm 0.82$ & 17.08 & 19.40 & $18.12 \pm 0.94$ & 16.85 & 19.60 & 0.462 \\
\hline Left Bd & $18.91 \pm 0.53$ & 18.11 & 19.44 & $18.14 \pm 0.59$ & 17.26 & 18.86 & 0.021 \\
\hline Right Dc & $9.98 \pm 0.68$ & 8.93 & 11.16 & $9.75 \pm 0.57$ & 8.84 & 10.51 & 0.529 \\
\hline Left Dc & $10.05 \pm 0.69$ & 9.31 & 11.29 & $9.89 \pm 0.54$ & 9.02 & 10.94 & 0.793 \\
\hline Right SD & $9.35 \pm 0.94$ & 8.08 & 10.62 & $9.51 \pm 0.57$ & 8.88 & 10.57 & 0.674 \\
\hline Left SD & $9.33 \pm 0.85$ & 8.45 & 10.59 & $9.22 \pm 0.35$ & 8.88 & 9.91 & 0.958 \\
\hline Right V & $8.57 \pm 1.31$ & 6.96 & 10.57 & $7.06 \pm 0.43$ & 6.55 & 8.57 & 0.012 \\
\hline Left V & $8.57 \pm 1.35$ & 6.94 & 10.71 & $6.93 \pm 0.55$ & 6.03 & 8.57 & 0.012 \\
\hline Right SA & $64.15 \pm 6.52$ & 50.96 & 71.02 & $59.24 \pm 4.81$ & 54.42 & 64.15 & 0.074 \\
\hline Left SA & $64.41 \pm 6.92$ & 51.36 & 71.48 & $59.59 \pm 4.62$ & 55.67 & 64.41 & 0.093 \\
\hline
\end{tabular}

${ }^{*} \mathrm{p}<$ 0.05: Mann-Whitney U test; SD — standard deviation; rest abbreviations — see Table 1

Table 3. " $r$ " values of Spearman's rho nonparametric correlations coefficients between the morphometric measurements of the femur in Van cats by gender

\begin{tabular}{|c|c|c|c|c|c|c|c|c|c|c|c|c|c|c|}
\hline \multirow[t]{2}{*}{ Female } & \multicolumn{14}{|c|}{ Male } \\
\hline & $\begin{array}{l}\text { Age } \\
\text { (A) }\end{array}$ & $\begin{array}{c}\text { Body } \\
\text { mass (W) }\end{array}$ & $\begin{array}{c}\text { Right } \\
\text { GL }\end{array}$ & $\begin{array}{l}\text { Left } \\
\text { GL }\end{array}$ & $\begin{array}{l}\text { Right } \\
\text { GLc }\end{array}$ & $\begin{array}{l}\text { Left } \\
\text { GLc }\end{array}$ & $\begin{array}{c}\text { Right } \\
\text { Bp }\end{array}$ & $\begin{array}{l}\text { Left } \\
\text { Bp }\end{array}$ & $\begin{array}{c}\text { Right } \\
\text { Bd }\end{array}$ & $\begin{array}{l}\text { Left } \\
\text { Bd }\end{array}$ & $\begin{array}{l}\text { Right } \\
\text { Dc }\end{array}$ & $\begin{array}{l}\text { Left } \\
\text { Dc }\end{array}$ & $\begin{array}{l}\text { Right } \\
\text { SD }\end{array}$ & $\begin{array}{l}\text { Left } \\
\text { SD }\end{array}$ \\
\hline Age (A) & & $0.957^{* *}$ & $0.878^{* *}$ & $0.878^{* *}$ & 0.293 & $0.830^{*}$ & 0.683 & 0.683 & 0.244 & -0.244 & 0.586 & $0.781^{*}$ & $0.732^{*}$ & 0.586 \\
\hline Body mass (W) & 0.390 & & $0.946^{* *}$ & $0.946^{* *}$ & 0.431 & $0.898^{* *}$ & 0.659 & 0.659 & 0.228 & -0.156 & 0.479 & $0.731^{*}$ & $0.874^{* *}$ & 0.683 \\
\hline Right GL & -0.098 & 0.286 & & $0.999 * *$ & 0.619 & $0.976^{* *}$ & 0.524 & 0.595 & 0.429 & 0.119 & 0.524 & $0.738^{*}$ & $0.881^{* *}$ & $0.714^{*}$ \\
\hline Left GL & -0.098 & 0.357 & $0.952^{* *}$ & & 0.619 & $0.976^{* *}$ & 0.524 & 0.595 & 0.429 & 0.119 & 0.524 & $0.738^{*}$ & $0.881^{* *}$ & $0.714^{*}$ \\
\hline Right GLC & -0.098 & 0.286 & $0.999 * *$ & $0.952^{* *}$ & & 0.571 & -0.095 & 0.262 & 0.310 & 0.476 & 0.381 & 0.405 & 0.571 & 0.333 \\
\hline Left GLc & 0.244 & 0.524 & $0.881^{* *}$ & $0.857^{* *}$ & $0.881^{* *}$ & & 0.500 & 0.643 & 0.524 & 0.190 & 0.571 & 0.690 & $0.810^{*}$ & 0.643 \\
\hline Right Bp & 0.488 & 0.643 & 0.476 & 0.405 & 0.476 & 0.524 & & 0.643 & 0.143 & -0.167 & 0.429 & $0.738^{*}$ & 0.595 & 0.667 \\
\hline Left Bp & -0.098 & 0.429 & 0.619 & 0.690 & 0.619 & 0.548 & 0.548 & & 0.167 & -0.143 & $0.833^{*}$ & 0.619 & 0.405 & 0.167 \\
\hline Right Bd & 0.634 & 0.333 & -0.214 & -0.143 & -0.214 & -0.048 & 0.595 & 0.357 & & $0.786^{*}$ & 0.500 & 0.548 & 0.286 & 0.381 \\
\hline Left Bd & $0.785^{*}$ & 0.515 & 0.096 & 0.108 & 0.096 & 0.323 & $0.802^{*}$ & 0.347 & $0.886^{* *}$ & & 0.190 & 0.238 & 0.143 & 0.262 \\
\hline Right Dc & 0.488 & 0.405 & -0.190 & -0.095 & -0.190 & 0.071 & 0.452 & 0.405 & $0.881 * *$ & $0.802^{*}$ & & $0.738^{*}$ & 0.238 & 0.095 \\
\hline Left Dc & 0.195 & 0.429 & 0.048 & 0.238 & 0.048 & 0.000 & 0.500 & 0.571 & $0.714^{*}$ & 0.563 & 0.571 & & 0.690 & 0.690 \\
\hline Right SD & -0.293 & 0.500 & 0.143 & 0.048 & 0.143 & 0.024 & 0.381 & 0.214 & -0.143 & -0.108 & -0.190 & 0.071 & & $0.881^{* *}$ \\
\hline Left SD & 0.049 & 0.667 & 0.167 & 0.071 & 0.167 & 0.190 & $0.714^{*}$ & 0.452 & 0.333 & 0.395 & 0.333 & 0.286 & $0.833^{*}$ & \\
\hline
\end{tabular}

${ }^{*} p<0.05 ;{ }^{* *} p<0.01$; abbreviations - see Table 1

values were found to be higher than left SD values in females and the difference was statistically significant $(p=0.036)$. Furthermore, male left Bd values were statistically higher than right $B d$ values $(p=0.017)$. No meaningful difference was determined for any other right and left side average femur values 
Table 4. Descriptive statistics and homotypic variations of the biometric parameters of the tibia obtained from three-dimensional reconstruction of computed tomography images in Van cats

\begin{tabular}{|c|c|c|c|c|c|c|c|}
\hline \multirow[t]{2}{*}{ Parameter } & \multicolumn{3}{|c|}{ Male } & \multicolumn{3}{|c|}{ Female } & \multirow[t]{2}{*}{$\mathbf{P}^{*}$} \\
\hline & Mean \pm SD & Minimum & Maximum & Mean \pm SD & Minimum & Maximum & \\
\hline Right GL1 & $113.27 \pm 4.84$ & 105.43 & 120.74 & $108.14 \pm 3.06$ & 103.27 & 112.80 & 0.059 \\
\hline Left GL1 & $113.57 \pm 5.48$ & 105.09 & 123.31 & $107.86 \pm 2.97$ & 102.42 & 110.81 & 0.036 \\
\hline Right Bp & $19.12 \pm 0.70$ & 18.17 & 19.95 & $18.31 \pm 0.54$ & 17.37 & 19.10 & 0.021 \\
\hline Left Bp & $19.07 \pm 0.90$ & 17.41 & 20.21 & $18.37 \pm 0.33$ & 17.81 & 18.77 & 0.052 \\
\hline Right Bd & $15.02 \pm 0.72$ & 14.34 & 16.11 & $13.80 \pm 0.61$ & 12.79 & 14.58 & 0.006 \\
\hline Left Bd & $15.31 \pm 0.67$ & 14.33 & 16.40 & $13.65 \pm 0.61$ & 12.71 & 14.47 & 0.001 \\
\hline Right SD & $8.16 \pm 0.68$ & 7.17 & 9.16 & $7.40 \pm 0.43$ & 6.89 & 8.05 & 0.036 \\
\hline Left SD & $7.91 \pm 0.79$ & 7.12 & 9.40 & $7.58 \pm 0.46$ & 6.99 & 8.08 & 0.674 \\
\hline Right V & $7.55 \pm 1.27$ & 6.05 & 9.50 & $6.18 \pm 0.51$ & 5.36 & 6.91 & 0.036 \\
\hline Left V & $7.57 \pm 1.28$ & 6.02 & 9.62 & $6.11 \pm 0.53$ & 5.30 & 7.01 & 0.021 \\
\hline Right SA & $56.84 \pm 6.48$ & 42.70 & 63.21 & $52.53 \pm 2.95$ & 47.49 & 57.00 & 0.027 \\
\hline Left SA & $56.94 \pm 6.46$ & 43.05 & 62.66 & $52.91 \pm 3.35$ & 47.81 & 56.94 & 0.093 \\
\hline
\end{tabular}

${ }^{*} \mathrm{p}<$ 0.05: Mann-Whitney U test; SD — standard deviation; other abbreviations — see Table 1

Table 5. " $r$ " values of Spearman's rho nonparametric correlations coefficients between the morphometric measurements of the tibia in Van cats by gender

\begin{tabular}{|c|c|c|c|c|c|c|c|c|c|c|}
\hline \multirow[t]{2}{*}{ Female } & \multicolumn{10}{|c|}{ Male } \\
\hline & Age (A) & Body mass (W) & Right GL1 & Left GL1 & Right Bp & Left Bp & Right Bd & Left Bd & Right SD & Left SD \\
\hline Age (A) & & $0.957^{* *}$ & $0.878^{* *}$ & $0.878^{* *}$ & $0.781^{*}$ & $0.830^{*}$ & 0.634 & 0.390 & $0.830^{*}$ & $0.781^{*}$ \\
\hline Body mass (W) & 0.390 & & $0.898^{* *}$ & $0.922^{* *}$ & $0.814^{*}$ & $0.814^{*}$ & 0.707 & 0.599 & $0.719^{*}$ & $0.731^{*}$ \\
\hline Right GL1 & -0.488 & 0.119 & & $0.952^{* *}$ & $0.762^{*}$ & $0.786^{*}$ & 0.595 & 0.476 & 0.643 & 0.571 \\
\hline Left GL1 & -0.342 & 0.262 & $0.929 * *$ & & 0.690 & $0.714^{*}$ & 0.619 & 0.476 & 0.667 & 0.571 \\
\hline Right Bp & 0.098 & 0.595 & 0.476 & 0.405 & & $0.905^{* *}$ & $0.762^{*}$ & 0.429 & 0.500 & $0.714^{*}$ \\
\hline Left Bp & 0.390 & 0.571 & 0.167 & 0.333 & 0.690 & & 0.476 & 0.357 & 0.571 & $0.810^{*}$ \\
\hline Right Bd & 0.488 & -0.310 & $-0.786^{*}$ & $-0.714^{*}$ & -0.333 & 0.167 & & 0.357 & 0.357 & 0.333 \\
\hline Left Bd & 0.098 & -0.476 & -0.429 & -0.405 & -0.095 & 0.286 & $0.810^{*}$ & & 0.238 & 0.381 \\
\hline Right SD & -0.025 & 0.060 & 0.431 & 0.467 & 0.407 & 0.192 & -0.443 & -0.084 & & $0.833^{*}$ \\
\hline Left SD & 0.537 & 0.524 & -0.024 & 0.214 & 0.048 & 0.167 & -0.262 & -0.452 & 0.515 & \\
\hline
\end{tabular}

${ }^{*} p<0.05 ;{ }^{* *} p<0.01 ;$ abbreviations - see Table 1

Table 6. Descriptive statistics and homotypic variations of the biometric parameters of the fibula obtained from three-dimensional reconstruction of computed tomography images in Van cats

\begin{tabular}{|c|c|c|c|c|c|c|c|}
\hline \multirow[t]{2}{*}{ Parameter } & \multicolumn{3}{|c|}{ Male } & \multicolumn{3}{|c|}{ Female } & \multirow[t]{2}{*}{$\mathbf{P}^{*}$} \\
\hline & Mean \pm SD & Minimum & Maximum & Mean \pm SD & Minimum & Maximum & \\
\hline Right GL2 & $105.09 \pm 5.08$ & 97.92 & 113.15 & $100.78 \pm 2.32$ & 97.28 & 103.99 & 0.074 \\
\hline Left GL2 & $105.67 \pm 6.22$ & 97.33 & 115.56 & $100.66 \pm 2.64$ & 96.84 & 104.18 & 0.074 \\
\hline Right V & $1.09 \pm 0.16$ & 0.90 & 1.29 & $0.83 \pm 0.05$ & 0.76 & 0.90 & 0.001 \\
\hline Left V & $1.10 \pm 0.18$ & 0.83 & 1.30 & $0.82 \pm 0.05$ & 0.73 & 0.90 & 0.003 \\
\hline Right SA & $14.07 \pm 1.60$ & 11.72 & 15.97 & $11.95 \pm 0.43$ & 11.15 & 12.60 & 0.012 \\
\hline Left SA & $14.28 \pm 1.62$ & 11.77 & 16.07 & $11.95 \pm 0.53$ & 11.21 & 12.56 & 0.012 \\
\hline
\end{tabular}

${ }^{*} \mathrm{p}<0.05$ : Mann-Whitney U test; SD — standard deviation; other abbreviations — see Table 1 
Table 7. " $r$ " values of Spearman's rho nonparametric correlations coefficients between the morphometric measurements of the fibula in Van cats by gender

\begin{tabular}{lcccc}
\hline Female & \multicolumn{4}{c}{ Male } \\
\cline { 2 - 5 } & Age (A) & Body mass (W) & Right GL2 & Left GL2 \\
\hline Age (A) & & $0.957^{* *}$ & $0.781^{*}$ & $0.878^{* *}$ \\
Body mass (W) & 0.390 & & $0.838^{* *}$ & $0.922^{* *}$ \\
Right GL2 & -0.195 & 0.333 & & $0.976^{* *}$ \\
Left GL2 & -0.293 & 0.310 & $0.952^{* *}$ \\
\hline
\end{tabular}

${ }^{* *} p<0.01 ;{ }^{*} p<0.05 ;$ abbreviations - see Table 1

( $p>0.05$ ). Femur volume was found as $8.57 \pm 1.33 \mathrm{~cm}^{3}$ in males and as $7.00 \pm 0.49 \mathrm{~cm}^{3}$ in females on average, while the surface area was calculated as $64.28 \pm$ $\pm 6.72 \mathrm{~cm}^{2}$ for males and as $59.42 \pm 4.72 \mathrm{~cm}^{2}$ for females, on average.

Table 3 shows the relationship between the morphometric values for femur based on sex. Accordingly, female cats have positive correlations between the following values $(p<0.05)$ : age and left Bd; right $\mathrm{GL}$ with left $\mathrm{GL}$, right $\mathrm{GLc}$, and left GLc; left GL with right GLc and left GLc; right GLc, and left GLc; right greatest breadth of the proximal end $(\mathrm{Bp})$ with left $B d$ and left $S D$; right $B d$ with left $B d$, right greatest depth of the caput ossis femoris (Dc), and left Dc; left $\mathrm{Bd}$ and right Dc; and finally, right SD and left SD. The male cats, on the other hand, were found to have positive correlations between the following values $(p<0.05)$ : between 'age and $W$ ' with right $G L$, left $G L$, left $\mathrm{GLc}$, left $\mathrm{Dc}$, and right $\mathrm{SD}$ values; right $\mathrm{GL}$ with left $G L$, left $G L c$, left $D c$, right $S D$, and left $S D$; left $G L$ with left GLc, left $D c$, right $S D$, and left SD; left GLc and right $\mathrm{SD}$; right $\mathrm{Bp}$ and left $\mathrm{Dc}$; left $\mathrm{Bp}$ and right $\mathrm{Dc}$; right $\mathrm{Bd}$ and left $\mathrm{Bd}$; right $\mathrm{Dc}$ and left $\mathrm{Dc}$; and finally, right SD and left SD.

The defining statistics for the morphometric values of tibia, and the comparisons in terms of homotypic variations, are provided in Table 4. Accordingly, male cats were found to have higher left GL1, right $B p$, right $B d$, left $B d$, right $S D$, right $V$, left $V$, and light surface area $(\mathrm{SA})$ values compared to females, and this difference was determined to be statistically significant $(p<0.05)$. No statistical difference in terms of measured left and right average tibia values was found, however $(p>0.05)$. Tibia volume was found as $7.56 \pm 1.28 \mathrm{~cm}^{3}$ on average for males and as for $6.15 \pm 0.52 \mathrm{~cm}^{3}$ females, while its SA was determined as $56.89 \pm 6.47 \mathrm{~cm}^{2}$ for males and as $52.72 \pm 3.15 \mathrm{~cm}^{2}$ for females, on average.
Table 5 presents the relationships between the morphometric values of tibia per sex. Accordingly, a positive correlation with $92.9 \%$ ratio was determined between the right GL1 and left GL1 values of the female cats, while a positive correlation with $81 \%$ ratio was determined between their right $\mathrm{Bd}$ and left $B d$ values $(p<0.05)$. Meanwhile, negative correlations for females between right Bd with right $\mathrm{GLI}$ and left GL1 values were determined with $78.6 \%$ and $71.4 \%$ ratio, respectively $(p<0.05)$. For male cats, a positive correlation was shown between age and $W$ values with right $G L 1$, left $G L 1$, right $B p$, left $B p$, right SD, and left SD values; between right GL1 with left $G L 1$, right $B p$ and left $B p$ values; between left $\mathrm{GL} 1$ and left $B p$ values; between right $B p$ with left $B p$, right $B d$, and left SD values; and between left SD with left $B p$ and right SD values $(p<0.05)$.

The defining statistics for the morphological values of fibula per sex and homotypic variations are provided in Table 6. Accordingly, male cats were found to have a higher left side SA value compared to the right side, and the difference was statistically significant $(p=0.012)$. No other statistical difference was determined between the right and left side tibia average values per sex $(p>0.05)$. That being said, right $V$, left $V$, right $S A$, and left $S A$ values were found to be higher in males compared to females in a statistically significant manner $(p<0.05)$. Fibula average volume was determined as $1.10 \pm 0.17 \mathrm{~cm}^{3}$ for males and as $0.83 \pm 0.05 \mathrm{~cm}^{3}$ for females, while its surface area was determined as $14.18 \pm 1.61 \mathrm{~cm}^{2}$ for males and as $11.95 \pm 0.48 \mathrm{~cm}^{2}$ for females.

Table 7 presents the relationship between the measured morphometric values for fibula bones. Accordingly, a positive correlation in male cats between age with $\mathrm{W}$, right $\mathrm{GL} 2$ and left $\mathrm{GL} 2$ values with $95.7 \%$, $78.1 \%$, and $87.8 \%$ ratio, respectively, while a positive correlation was found between $\mathrm{W}$ with right $\mathrm{GL} 2$ and left GL2 values with $83.8 \%$ and $92.2 \%$ ratios, and between right $\mathrm{GL} 2$ and left $\mathrm{GL} 2$ values with $97.6 \%$ ratio $(p<0.05)$. Similarly, a positive correlation between right GL2 and left GL2 values was determined for females with $95.2 \%$ as well $(p<0.01)$.

\section{DISCUSSION}

Studies on the morphology of animal bones yield important data for a variety of developmental, evolutionary and forensic sciences. Studies on the morphometric and volumetric analyses and morphology of the long bones, in particular, are of great help in 
determining crucial behavioural activities that differ among animal species, such as foraging, hunting, evading hunters, and migration; as well as their phylogeny, allometry and postures. In addition, these measurements hold an important place in determining morphological variations and taxonomic classifications among different species of the same genus; as well as identifying the differences between sexes $[5,23,38]$. For this purpose, many studies have been conducted on humans $[21,22,42]$ and animals $[2,5,9,10,14,16,29,33,36]$ that involved obtaining osteometric measurements on the long bones of their pelvic limbs. In our study, the morphometric, volumetric and surface area measurements of the femur, tibia, and fibula of adult Van cats were obtained via CT scans and 3D modelling, in order to identify the differences between the two sexes. According to these statistics, the right $G L$, left $G L$, right GLc, left $B d$, right $V$, and left $V$ values of the femur, the left $G L 1$, right $B p$, right $B d$, left $B d$, right $S D$, right $V$, left $V$, and right $S A$ values of the tibia, and the right $V$, left $V$, right $S A$, and left $S A$ values of the fibula are higher in male cats than that of female cats in a statistically significant fashion $(p<0.05)$. Most of the other measurements were likewise found to be higher in male cats. We can, therefore, surmise that the femur, tibia and fibula of the male cats are larger than that of the female cats. We think that the larger bones of the pelvic limbs in male Van cats are correlates to the body mass as well as the bones in thoracic limbs according to data obtained from the previous studies by Yilmaz [48].

In the study conducted by Pazar and Kahvecioğlu [36] on 15 male and 15 female New Zealand rabbits, the researchers found no significant difference between the morphometric properties on the long bones of the right and left pelvic limbs $(p>0.05)$. In the present study, although no statistically significant difference was found between the morphometric values of the right and left tibia and fibula of different sexes $(p>0.05)$, it has been observed that in female cats, the femur right SD value is higher than the left SD value, and in male cats, the femur left Bd value is higher than the right $B d$ value in a statistically significant manner $(p<0.05)$. These results are thought to be important for the evaluation of unilateral studies of the pelvic limb long bones in Van cats.

In their study, Boonsri et al. [5] report that the GL values of the femur, tibia and fibula of cats with the dolichocephalic and mesaticephalic skulls are $108.95 \pm 5.14$ and $95.37 \pm 12.39 \mathrm{~mm}$, $110.12 \pm 5.39 \mathrm{~mm}$ and $96.88 \pm 12.69 \mathrm{~mm}$, and $101.75 \pm 6.01$ and $84.53 \pm 17.50 \mathrm{~mm}$, respectively. In the same study, the measurements of these bones belonging to male and female domestic cats were reported to be $103.64 \pm 12.80 \mathrm{~mm}$ and $101.22 \pm 10.74 \mathrm{~mm}$, $105.65 \pm 12.48 \mathrm{~mm}$ and $102.07 \pm 10.57 \mathrm{~mm}$, and $94.79 \pm 17.13 \mathrm{~mm}$ and $93.21 \pm 12.07 \mathrm{~mm}$, respectively. In Turkish Van cats, these values in male and female cats were, respectively, $108.84 \pm 4.93 \mathrm{~mm}$ and $103.31 \pm 2.93 \mathrm{~mm}, 113.42 \pm 5.16 \mathrm{~mm}$ and $108.00 \pm 3.02 \mathrm{~mm}$, and $105.38 \pm 5.65 \mathrm{~mm}$ and $100.72 \pm 2.48 \mathrm{~mm}$. It is thought that in general, the marginal differences among these values that are otherwise in compliance with literature, and the difference can be attributed to factors such as age, length, body weight, breed and measuring techniques. In addition, according to these values, the Van cats are similar to cats with a dolichocephalic skull shape in terms of pelvic limb long bone dimensions.

Studies show that there is a close relation between age and body weight with the evaluation of long bones of the hind legs; or the development of these bones, especially from a young age $[2,7,20]$. It has also been found that there is a generally positive correlation between the morphometric measuring parameters of these bones [5]. Our study shows, regarding the properties of the femur based on sex, that there is a significant positive relationship between the age and body mass (W) with right $G L$, left $G L$, left $G L c$, left $D c$, and right SD values of male cats, as well as the age and left Bd values of female cats $(p<0.05)$. On the other hand, while there is a positive correlation between body mass and morphometric parameters, no significant relationship could be found ( $p>0.05)$. Regarding the measurements of tibia based on sex, while a positive relationship between the age and body mass with right $G L 1$, left $G L 1$, right $B p$, left $B p$, right $S D$, and left SD values in male cats was observed, no statistically significant relationship between age and body mass and these values were noted in female cats $(p>0.05)$. Regarding fibula measurements and sex, although there was a positive relationship between age and body mass (W) with right GL2 and left GL2 in male cats; there was only a positive relationship of $95.2 \%$ in right $\mathrm{GL} 2$ and left $\mathrm{GL} 2$ values in female cats $(p<0.01)$. The correlation between the measurements of femur, tibia, and fibula of male and 
female cats are provided in the Tables 3, 5, and 7. In general, we can interpret that there is a positive correlation between age and body mass with the measurement values of the long bones in the pelvic limbs in Van cats.

Thanks to the recent developments in CT and 3D reconstruction software, it has become possible to obtain images of any desired width from an anatomical section without any physical harm to the animal, and the morphometric, volumetric and surface area measurements can now be obtained in a fast and efficient way. In this manner, the efficacy of the diagnosis and treatment of various pathological conditions afflicting the anatomical area of interest can also be evaluated $[21,26,46]$. A literature survey has shown that, while the volumetric and surface area measurements of the long bones of pelvic limbs belonging to humans [21], brown bears [13], chinchillas [33], guinea pigs [11], and gazelles [12] have been obtained using $\mathrm{CT}$ and $3 \mathrm{D}$ imaging software, no information regarding the long bones of pelvic limbs of cats could be found in literature in that regard. The mean volumetric values of the femur were $8.57 \pm$ $\pm 1.33 \mathrm{~cm}^{3}$ in males and $7.00 \pm 0.49 \mathrm{~cm}^{3}$ in females; while their mean surface areas were $64.28 \pm 6.72 \mathrm{~cm}^{2}$ in males and $59.42 \pm 4.72 \mathrm{~cm}^{2}$ in females. The mean volumetric values of the tibia were $7.56 \pm 1.28 \mathrm{~cm}^{3}$ in males and $6.15 \pm 0.52 \mathrm{~cm}^{3}$ in females; while their mean surface areas were $56.89 \pm 6.47 \mathrm{~cm}^{2}$ in males and $52.72 \pm 3.15 \mathrm{~cm}^{2}$ in females. The mean volumetric values of the fibula were $1.10 \pm 0.17 \mathrm{~cm}^{3}$ in males and $0.83 \pm 0.05 \mathrm{~cm}^{3}$ in females; while their mean surface areas were $14.18 \pm 1.61 \mathrm{~cm}^{2}$ in males and $11.95 \pm 0.48 \mathrm{~cm}^{2}$ in females. The average volume and surface area measurement values in pelvic limb long bones are higher in male Van cats. It is thought that this difference detected between the measurement values of these bones may be related to body mass.

\section{CONCLUSIONS}

In conclusion, the sex-based differences of the measured parameters of the femur, tibia and fibula belonging to adult Van cats were detected. We believe that the information gathered in this study can be utilised in determining morphological variations and the taxonomy of different lineages of Van cats. Moreover, this study has hopefully uncovered information that will be beneficial to the clinical studies of veterinarians that seek to treat Van cats' pathological conditions of the osteological structure, and for zooarchaeologists.

\section{REFERENCES}

1. Ajayi IE, Shawulu JC, Zachariya TS, et al. Osteomorphometry of the bones of the thigh, crus and foot in the New Zealand white rabbit (Oryctolagus cuniculus). Ital J Anat Embryol. 2012; 117(3): 125-134, indexed in Pubmed: 23420943.

2. Alpak H, Onar V, Mutuş R. The relationship between morphometric and long bone measurements of the Morkaraman sheep. Turk J Vet Anim Sci. 2009; 33(3): 199-207, doi: 10.3906/vet-0709-23.

3. Atalar Ö, Özdemir D. Macro-anatomical investigatios on the skeletons of marten (Martes fonia). II. Ossa Membri Pelvini. Firat Univ J Health Sci. 2002; 16: 233-236.

4. Bahadır A, Yıldız H. Veteriner Anatomi: Hareket Sistemi \& iç Organlar. Ezgi Kitabevi Bursa, Turkey 2014.

5. Boonsri B, Pitakarnnop T, Buddhachat K, et al. Can feline (Felis catus) flat and long bone morphometry predict sex or skull shape? Anat Sci Int. 2019; 94(3): 245-256, doi: 10.1007/s12565-019-00480-8, indexed in Pubmed: 30771106.

6. Cak B. Turkish Van Cat and Turkish Angora Cat: A Review. J Agric Sci Technol A. 2017; 7(3): 151-159, doi: 10.17265/2161-6256/2017.03.002.

7. Campbell KE, Marcus L. The relationships of hindlimb bone dimensions to body weight in birds. Nat Hist Mus Los Angeles Co Sci Ser. 1992; 36: 395-412.

8. Carew RM, Morgan RM, Rando C. A preliminary investigation into the accuracy of 3D modeling and 3D printing in forensic anthropology evidence reconstruction. J Forensic Sci. 2019; 64(2): 342-352, doi: 10.1111/15564029.13917, indexed in Pubmed: 30296344.

9. Casteleyn C, Bakker J, Breugelmans S, et al. Anatomical description and morphometry of the skeleton of the common marmoset (Callithrix jacchus). Lab Anim. 2012; 46(2): 152-163, doi: 10.1258/la.2012.011167, indexed in Pubmed: 22517992.

10. Çevik-Demirkan A, Özdemir V, Türkmenoğlu i, et al. Anatomy of the hind limb skeleton of the chinchilla (Chinchilla lanigera). Acta Veterinaria Brno. 2007; 76(4): 501-507, doi: 10.2754/avb200776040501.

11. Dayan MO, Beşoluk K, Eken E, et al. Three-dimensional modelling of the femur and humerus in adult male guinea pigs (guinea pig) with computed tomography and some biometric measurement values. Folia Morphol. 2019; 78(3): 588-594, doi: 10.5603/FM.a2019.0002, indexed in Pubmed: 30644082.

12. Demircioglu I, Gezer Ince N. Three-dimensional modelling of computed tomography images of limb bones in gazelles (Gazella subgutturosa). Anat Histol Embryol. 2020; 49(6): 695-707, doi: 10.1111/ahe.12564, indexed in Pubmed: 32319123.

13. Demircioğlu i, Kirbaş Doğan G, Aksünger Karaavci F, et al. Three-dimensional modelling and morphometric investigation of computed tomography images of brown bear's (Ursus arctos) ossa cruris (Zeugopodium). Folia Morphol. 2020; 79(4): 811-816, doi: 10.5603/FM.a2019.0125, indexed in Pubmed: 31777947.

14. Dursun N. Veterinary anatomy I. Medisan Publisher, Ankara, Turkey 2008.

15. Dyce KM, Sack WO, Wensing CJG. Textbook of veterinary anatomy, 4th ed. Saunders Elsevier Inc., Missouri, United States 2010: 490-500.

16. El-Ghazali HM, El-Behery El. Comparative morphological interpretations on the bones of the pelvic limb of New Zea- 
land rabbit (Oryctolagus cuniculus) and domestic cat (Felis domestica). J Adv Vet Anim Res. 2018; 5(4): 410-419, doi: 10.5455/javar.2018.e292, indexed in Pubmed: 31453151.

17. Imai $N$, Funayama $K$, Suzuki $H$, et al. Stature estimation formulae based on bony pelvic dimensions and femoral length. Homo. 2020; 71(2): 111-119, doi: 10.1127/ homo/2020/1116, indexed in Pubmed: 31944200.

18. Kalra MK, Maher MM, Toth $T L$, et al. Strategies for $C T$ radiation dose optimization. Radiology. 2004; 230(3): 619-628, doi: 10.1148/radiol.2303021726, indexed in Pubmed: 14739312.

19. Karan M. Macro-anatomical study of ossa membri pelvini in the feral pigs (Sus scrofa). Firat Univ Vet J HIth Sci. 2012; 26: 31-34.

20. Kumaş $M$, Ayaz D. Age determination and long bone histology in Stellagama stellio (Linnaeus, 1758 ) ( Squamata: Sauria: Agamidae ) populations in Turkey. Vertebr Zool. 2014; 64(1): 113-126.

21. Lee UY, Kim IB, Kwak DS. Sex determination using discriminant analysis of upper and lower extremity bones: New approach using the volume and surface area of digital model. Forensic Sci Int. 2015; 253: 135.e1-135.e4, doi: 10.1016/j.forsciint.2015.05.017, indexed in Pubmed: 26117502.

22. Mahakkanukrauh P, Khanpetch P, Prasitwattanseree S, et al. Stature estimation from long bone lengths in a Thai population. Forensic Sci Int. 2011; 210(1-3): 279.e1-279.e7, doi: 10.1016/j.forsciint.2011.04.025, indexed in Pubmed: 21616616.

23. Martín-Serra A, Figueirido B, Palmqvist P. A three-dimensional analysis of the morphological evolution and locomotor behaviour of the carnivoran hind limb. BMC Evol Biol. 2014; 14: 129, doi: 10.1186/1471-2148-14-129, indexed in Pubmed: 24927753.

24. Monchot $\mathrm{H}$, Gendron D. Disentangling long bones of foxes (Vulpes vulpes and Alopex lagopus) from arctic archaeological sites. J Archaeol Sci. 2010; 37(4): 799-806, doi: 10.1016/j.jas.2009.11.009.

25. Nomina Anatomica Veterinaria. International committee on veterinary gross anatomical nomenclature (ICVGAN), Published by the Editorial Committee, Hannover, 2017.

26. Ohlerth S, Scharf G. Computed tomography in small animals--basic principles and state of the art applications. Vet J. 2007 ; 173(2): 254-271, doi: 10.1016/j. tvjl.2005.12.014, indexed in Pubmed: 16516508.

27. Olude MA, Olopade JO, Mustapha OA. Macro-anatomical investigations of the skeletons of the African giant rat (Cricetomys gambianus Waterhouse): Pelvic limb. Eur J Anat. 2009; 13(3): 127-131.

28. Onar V, Belli O. Estimation of shoulder height from long bone measurements on dogs unearthed from the Van-Yoncatepe early Iron Age necropolis in Eastern Anatolia. Rev Med Vet (Toulouse). 2005; 156(1): 53-60, doi: 10.1007/ s12565-019-00480-8.

29. Onwuama KT, Ojo SA, Hambolu JO, et al. Macro-anatomical and morphometric studies of the hindlimb of grasscutter (Thryonomys swinderianus, Temminck-1827). Anat Histol Embryol. 2018; 47(1): 21-27, doi: 10.1111/ ahe.12319, indexed in Pubmed: 29139158.

30. Ozgel O, Aykut M. Macroanatomical investigation on the ossa membri pelvini of Anatolian bobcat, Lynx lynx. Pakistan J Zool. 2015; 47(5): 1492-1494.

31. Özdemir D, Atalar Ö. Macro-anatomical investigations on the skeletons of squirrel (Sciurus vulgaris). II. Ossa Membri Pelvini. Fırat Univ J Health Sci. 2003; 17: 151-154.
32. Özdemir D, Karan M. Macroanatomical investigations on the skeletons of badger (Meles meles). II.Ossa membri pelvini. FIrat Univ J Health Sci. 2001; 15: 397-400.

33. Özkadif S, Varlik A, Kalaycı I, et al. Morphometric evaluation of chinchillas (Chinchilla lanigera) femur with different modelling techniques. Kafkas Univ Vet Fak Derg. 2016; 22(6): 945-951, doi: 10.9775/kvfd.2016.15683.

34. Özkan ZE. Macro-anatomical investigations on the hind limb skeleton of mole-rat (Spalax leucodon Nordmann). Vet Arhiv . 2002a; 72: 159-166.

35. Özkan ZE. Macro-anatomical investigations on the skeletons of hedgehog (Erinaceus europaeus L.) II Ossa membri pelvini . Vet Arhiv . 2002b; 72: 213-220.

36. Pazvant G, Kahvecioğlu KO. Studies on homotypic variation of forelimb and hindlimb long bones of rabbits. J Fac Vet Med Istanbul Univ. 2009; 35: 23-39.

37. Pazvant G, Kahvecioğlu KO. Studies on homotypic variations of forelimb and hindlimb long bones of guinea pigs. J Fac Vet Med Istanbul Univ. 2013; 39: 20-32.

38. Polly PD. Limbs in Mammalian Evolution. In: Fins into Limbs. Evolution, development and transformation, Chapter 15, Hall BK (ed.). University of Chicago Press, Chicago 2007: 245-268.

39. Prokop M. General principles of MDCT. Eur J Radiol. 2003; 45(Suppl 1): S4-10, doi: 10.1016/s0720-048x(02)00358-3, indexed in Pubmed: 12598021.

40. Saber A, K. B. Some morphological and radiological studies on the pelvic limb skeleton of Lumholtz Tree-Kangaroo (Dendrolagus lumholtzii). Journal of Veterinary Anatomy. 2019; 12(1): 19-34, doi: 10.21608/jva.2019.67223.

41. Salinas $P$, Arenas-Caro A, Núñez-Cook S, et al. Morphometric, anatomic and radiographic study of bone of the pelvic limb of endangered patagonian huemul deer (hippocamelus bisulcus). Int J Morphol. 2020; 38(3): 747-754, doi: 10.4067/s0717-95022020000300747.

42. Saulsman B, Oxnard CE, Franklin D. Long bone morphometrics for human from non-human discrimination. Forensic Sci Int. 2010; 202(1-3): 110.e1-110.e5, doi: 10.1016/j. forsciint.2010.05.009, indexed in Pubmed: 20837249.

43. Shahar R, Milgram J. Morphometric and anatomic study of the hind limb of a dog. Am J Vet Res. 2001; 62(6): 928-933, doi: 10.2460/ajvr.2001.62.928, indexed in Pubmed: 11400852.

44. Von Den Driesch A. A guide to the measurement of animal bones from archaeological sites. Peabody Museum Bulletin 1. Harvard University, Cambridge, MA 1976.

45. Wisner ER, Zwingenberger AL. Atlas of small animal CT and MRI. Willey-Blackwell Publishing, USA 2015: 40-68.

46. Yilmaz O, Soyguder Z, Yavuz A, et al. Three-dimensional computed tomographic examination of pelvic cavity in Van Cats and its morphometric investigation. Anat Histol Embryol. 2020; 49(1): 60-66, doi: 10.1111/ahe.12484, indexed in Pubmed: 31486129.

47. Yilmaz O, Soyguder Z, Yavuz A. Three-dimensional investigation by computed tomography of the clavicle and scapula in van cats. Van Vet J. 2020; 31(1): 34-41, doi: 10.36483/vanvetj.644080.

48. Yilmaz $\mathrm{O}$. Three-dimensional investigation by computed tomography of the forelimb skeleton in van cats. Van Yuzuncu Yil University, Institute of Health Sciences, Faculty of Veterinary, Department of Anatomy, Van, Turkey 2018.

49. Yilmaz S, Dinç G, Aydın A. Macro-Anatomical Investigations on the Skeletons of Porcupine (Hystrix Cristata) II. Ossa Membri Pelvini. Turk J Vet Anim Sci. 1999; 23(3): 297-300. 